\title{
Osteoinduction by combining bone morphogenetic protein (BMP)-2 with a bioactive novel nanocomposite
}

\section{A. Sharma, F. Meyer, M. Hyvonen, S. M. Best, R. E. Cameron, N. Rushton}

From Department of Materials, University of Cambridge, Cambridge, United Kingdom

A. Sharma, MBBS, MRCS, MRCSEd, MPhil(Cantab), Orthopaedic Registrar University of Cambridge, Department of Materials Science, Pembroke Street, Cambridge CB2 3QZ, UK.

- F. Meyer, PhD, University Lecturer

University Hospital of Strasbourg, Department of Biological Sciences, Faculty of Dental Surgery, 1 Place de l'Hôpital, 67000 Strasbourg, France.

M. Hyvonen, PhD, University Lecturer

University of Cambridge, Department of Biochemistry, Hopkins Building, Downing Site, Cambridge CB2 1QW, UK.

S. M. Best, PhD, Professor of Materials

R. E. Cameron, PhD, Professor of Materials

University of Cambridge, Department of Materials Science and Metallurgy, Pembroke Street, Cambridge CB2 3QZ, UK.

N. Rushton, MD, FRCS, Professor of Orthopaedics University of Cambridge, Orthopaedic Research Unit, Addenbrooke's Hospital, Hills Road, Cambridge CB2 2QQ, UK.

Correspondence should be sent to Mr A. Sharma; e-mail: aman.sharma@ndorms.ox.ac.uk

10.1302/2046-3758.17.2000082 $\$ 2.00$

Bone Joint Res 2012;1:145-51. Received 12 April 2012; Accepted after revision 30 May 2012

\section{Objectives}

There is increasing application of bone morphogenetic proteins (BMPs) owing to their role in promoting fracture healing and bone fusion. However, an optimal delivery system has yet to be identified. The aims of this study were to synthesise bioactive BMP-2, combine it with a novel $\alpha$-tricalcium phosphate/poly(D,L-lactide-co-glycolide) ( $\alpha$-TCP/PLGA) nanocomposite and study its release from the composite.

\section{Methods}

BMP-2 was synthesised using an Escherichia coli expression system and purified. In vitro bioactivity was confirmed using $\mathrm{C} 2 \mathrm{C} 12$ cells and an alkaline phosphatase assay. The modified solution-evaporation method was used to fabricate $\alpha$-TCP/PLGA nanocomposite and this was characterised using $X$-ray diffraction and scanning electron microscopy. Functionalisation of $\alpha$-TCP/PLGA nanocomposite by adsorption of BMP-2 was performed and release of BMP-2 was characterised using an enzyme-linked immunosorbent assay (ELISA).

\section{Results}

Alkaline phosphatase activity of $\mathrm{C} 2 \mathrm{C} 12$ cells was increased by the presence of all BMP-2/ nanocomposite discs compared with the presence of a blank disc $(p=0.0022)$, and increased with increasing incubation concentrations of BMP-2, showing successful adsorption and bioactivity of BMP-2. A burst release profile was observed for BMP-2 from the nanocomposite.

\section{Conclusions}

Functionalisation of $\alpha$-TCP/PLGA with BMP-2 produced osteoinduction and was dosedependent. This material therefore has potential application as an osteoinductive agent in regenerative medicine.

Keywords: Osteoinduction, BMP-2, Nanocomposite, Polymer, Ceramics, Tissue engineering, Orthopaedics

\section{Article focus}

- Can bone morphogenetic protein (BMP)2 be delivered from a bioresorbable nanocomposite?

Key messages

- This polymer/ceramic nanocomposite supports osteoblastic growth

- The use of BMP-2 combined with bioactive nanocomposite represents an alternative approach for bone regeneration

\section{Strengths and limitations}

- No comparison of BMP-2 derived from Escherichia coli with commerciallyavailable BMP-2 from mammalian expression systems
The nanocomposite was not compared to a similar microcomposite

- Successful synthesis of nanocomposite and E. coli-derived BMP-2

- Successful BMP-2 adsorption onto nanocomposite

\section{Introduction}

Bone morphogenetic proteins (BMPs) have been known to promote fracture healing since their discovery in the 1960s by Marshall Urist. ${ }^{1}$ Over the past decade there has been considerable interest in their clinical application, particularly with respect to nonunion and spinal surgery. Nonunion is a relatively common complication of fractures, with rates of between $5 \%$ and $10 \%{ }^{2}$ 
Traditionally, bone grafting procedures ${ }^{3}$ and segmental bone transport ${ }^{4}$ have been employed for bone tissue regeneration. However, their limited availability, donor site morbidity and increased costs mean that there is still a need for alternative methods, ${ }^{3,5}$ which has led to considerable research into regeneration using BMPs. The United States Food and Drug Administration (FDA) has given approval to two BMP-products: INFUSE (Medtronic, Minneapolis, Minnesota) and OP-1 Putty/Implant (Stryker, Newbury, United Kingdom). There remains a need to identify improved and cost-effective delivery systems if BMPs are to be widely used.

Although BMPs have tremendous potential for inducing bone growth, they have a short half-life (approximately six minutes in non-human primates), and their rapid clearance from the site of application continues to drive the need to find an optimal delivery system. ${ }^{6}$ It has been postulated that delivery systems can modulate the clinical efficacy of BMPs and, for them to be effective, the carrier should be able to ensure that they are delivered in adequate concentrations and to the anatomical site of interest. $^{7}$

The main difficulty associated with the delivery of BMP is their retention at the site of injury, in order to optimise their osteogenic potential. The critical factor that affects their retention is the delivery system used. It should be biodegradable while protecting the BMPs from degradation, and it should stimulate a minimal inflammatory response but allow vascularisation and ingress of cells. ${ }^{8,9}$ As with other delivery systems for in vivo use, it should neither be toxic nor carcinogenic. It should be easily sterilised, stable and cost-effective. ${ }^{8,9}$

In addition, the optimal concentration of BMP at the defect site has not yet been determined, although it depends on the size of the defect, its vascularisation and the delivery system being used. ${ }^{10}$ Clearly, the lower the dose that can be used to enhance osteogenesis, the lower the risk of side-effects such as ectopic bone formation, as BMPs are capable of osteoinduction in non-bony sites. ${ }^{11}$

The aims of our research were to synthesise and study the release of BMP-2 from a bioresorbable osteoconductive nanocomposite and to assess its suitability for tissue regeneration.

\section{Materials and Methods}

Synthesis and characterisation of $\alpha$-TCP/PLGA nanocomposite. $\alpha$-tricalcium phosphate ( $\alpha-T C P)$ was synthesised by a wet precipitation reaction between calcium hydroxide $\left(\mathrm{Ca}(\mathrm{OH})_{2}\right)$ (VWR International, Lutterworth, United Kingdom) and orthophosphoric acid $\left(\mathrm{H}_{3} \mathrm{PO}_{4}\right)$ (Acros Organics, Geel, Belgium) at a molar ratio of 3:2. The orthophosphoric acid solution was added to the calcium hydroxide solution and stirred for a further three hours. After 24 hours at room temperature, it was filtered and then dried for a further 24 hours. After grinding, the powder was sintered at $1400^{\circ} \mathrm{C}$ for four hours and quenched to room temperature. The powder was characterised using X-ray diffraction (XRD) (X'Pert Philip PW3020; PANalytical, Almelo, The Netherlands), X-ray fluorescence spectroscopy (XRF) (Scandinavian Metallurgical Co Ltd, Rotherham, United Kingdom), scanning electron microscopy (SEM) (JEOL-JSM6340F; JEOL LTD, Welwyn Garden City, United Kingdom), transmission electron microscopy (TEM) (JEOL-200CX; JEOL LTD) and particle size analysis (Mastersizer Hydro 2000MU(A); Malvern Instruments Ltd, Malvern, United Kingdom).

Using poly(D,L-lactide-co-glycolide) (PLGA; Lakeshore Biomaterials, Birmingham, Alabama) 50:50, $\alpha$-TCP and acetone, a nanocomposite comprising of $30 \% \alpha-$ TCP was produced by a modified solution evaporation (MSE) method. ${ }^{12}$ The $\alpha$-TCP/PLGA nanocomposite was then hotpressed into $50 \mathrm{~mm} \times 1 \mathrm{~mm}$ sheets using thermocompression. The nanocomposite was characterised using SEM, thermogravimetric analysis (TGA), and energy dispersive $x$-ray spectrometry (EDX).

Synthesis of BMP-2. An Escherichia coli expression system (BL21DE3) was used to express recombinant BMP-2 (synthetic gene coding for mature BMP-2 was cloned into pET30a vector by Genscript (Piscataway, New Jersey)). Isopropyl $\beta$-D-1-thiogalactopyranoside was used to induce protein expression and inclusion bodies were then isolated and solubilised. Protein refolding was performed in Tris-containing PPS (3-(1-pyridinio)-1-propanesulfonate) buffer (Sigma-Aldrich, Dorset, United Kingdom) and the BMP-2 was purified using reversephase and ion exchange chromatography (ÄKTA purifier; GE Healthcare, Amersham, United Kingdom).

BMP-2 functionalisation of $\alpha$-TCP/PLGA nanocomposite. Discs measuring $8 \mathrm{~mm} \times 1 \mathrm{~mm}$ of $30 \% \alpha$-TCP/PLGA nanocomposite were made using a die punch kit and their surface was made rough using silicon carbide sandpaper. After being cleaned in $100 \%$ ethanol and exposed to ultraviolet light for 15 minutes, the discs were incubated in BMP-2/PBS solutions in polypropylene tubes overnight at room temperature with shaking, and adsorption of BMP-2 was tested using a direct enzyme-linked immunosorbent assay (ELISA). Bioactivity of these discs was assessed using alkaline phosphatase (ALP) assay.

Cell culture. C2C12 cells were grown in Dulbecco's modified Eagle's medium supplemented with $4.5 \mathrm{~g} / \mathrm{l}$ glucose, $10 \%$ foetal bovine serum and $1 \%$ penicillin/streptomycin/ L-glutamine at $37^{\circ} \mathrm{C}$ in a humidified atmosphere of $5 \% \mathrm{CO}_{2}$.

Quantification of BMP-2 released/adsorbed by ELISA assay. Duplicates of each test and control solution were placed in each well of a 96-well plate that was sealed and incubated at $4^{\circ} \mathrm{C}$ overnight. The plate was emptied (for the quantification of BMP-2 adsorbed onto discs, the discs were added to empty wells at this stage) and assay buffer (PBS/4\% bovine serum albumin) was added and incubated at room temperature for one hour. After washing with PBS $/ 0.1 \%$ Tween 20, anti-BMP-2 antibody 

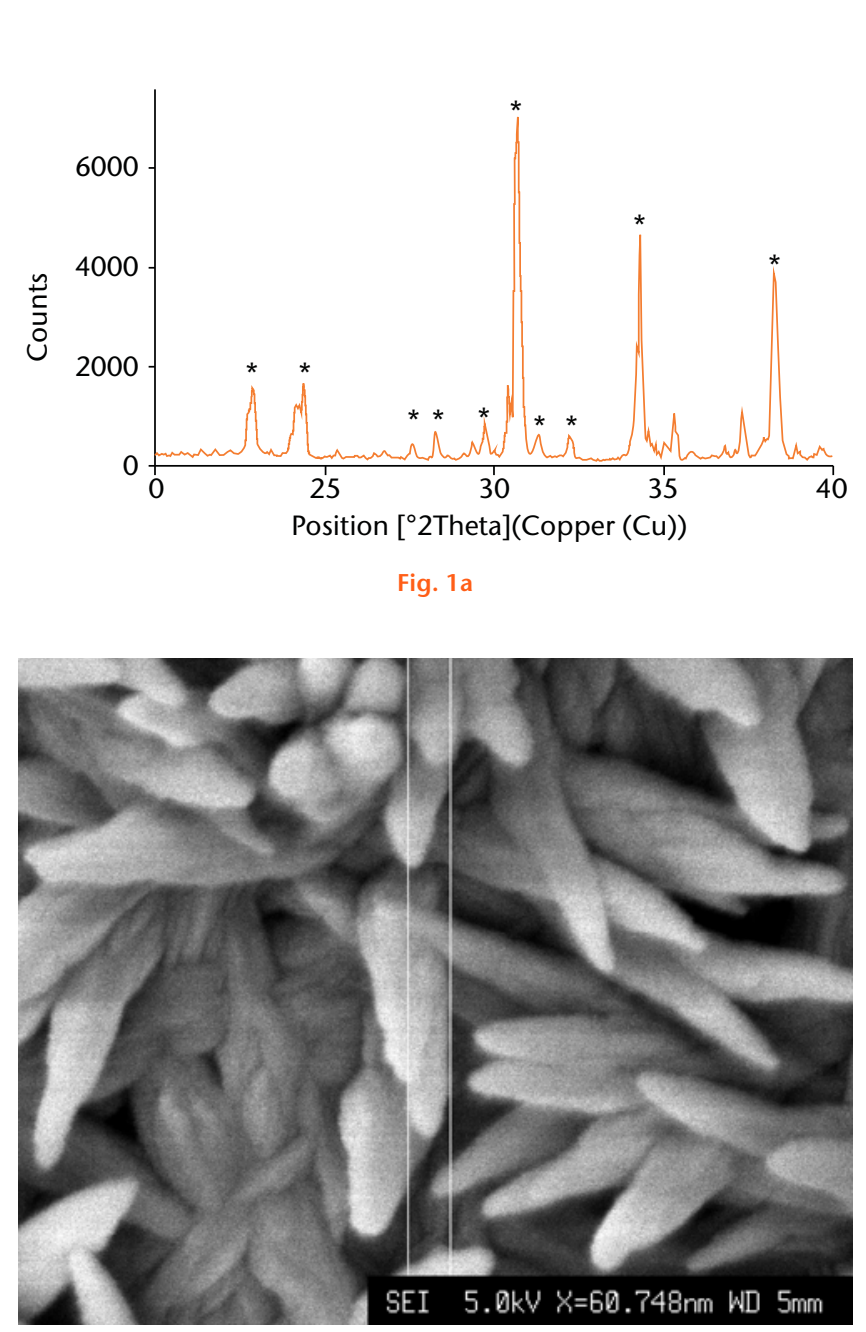

Fig. $1 \mathrm{~b}$

Figure $1 \mathrm{a}$ - plot showing characterisation of $\alpha$-tricalcium phosphate ( $\alpha$-TCP), with the X-ray diffraction pattern of $\alpha$-TCP sintered at $1400^{\circ} \mathrm{C}$. The asterisks denote $\alpha$-TCP. Figure $1 b-$ scanning electron microscopy image of $\alpha$-TCP at $\times 60000$ magnification.

(MAB3551; R\&D Systems, Abingdon, United Kingdom) was added and the plate was incubated for two hours at room temperature. The plate was washed and horseradish peroxidase (HRP)-conjugated secondary antibody was added. The plate was incubated for two hours at room temperature and washed. HRP substrate reagent (R\&D Systems) was added, incubated for 20 minutes at room temperature in the dark and the reaction then stopped by the addition of $2 \mathrm{M}$ sulphuric acid. Absorbance was measured at $450 \mathrm{~nm}$ wavelength.

In vitro release of BMP-2. Discs (in triplicate) of $30 \% \alpha$ TCP/PLGA/BMP-2 nanocomposite were incubated in $500 \mu \mathrm{l}$ PBS at room temperature for 72 hours, with shaking at $200 \mathrm{rpm}$. PBS solution containing released BMP-2 was harvested at one, two, four, six, eight, ten, 12, 24, 48 and 72 hours, and at each time point was replaced with $500 \mu \mathrm{l}$ of fresh PBS. The harvested PBS was stored at
Table I. Sintering resulted in an increase in surface- and volume-weighted mean sizes of $\alpha$-TCP particles

\begin{tabular}{llllll}
\hline & $\begin{array}{l}\mathbf{d}(\mathbf{0 . 1}) \\
(\mathbf{\mu m})\end{array}$ & $\begin{array}{l}\mathbf{d}(\mathbf{0 . 5}) \\
(\mathbf{\mu m})\end{array}$ & $\begin{array}{l}\text { d(0.9) } \\
\mathbf{( \mu m )}\end{array}$ & $\begin{array}{l}\text { Surface } \\
\text { weighted } \\
\text { mean } \\
\mathbf{d}(\boldsymbol{\mu m})\end{array}$ & $\begin{array}{l}\text { Volume } \\
\text { weighted } \\
\text { mean } \\
\mathbf{d}(\boldsymbol{\mu m})\end{array}$ \\
\hline $\begin{array}{l}\alpha-T C P \text { paste } \\
\text { (before } \\
\text { sintering) }\end{array}$ & 4.316 & 13.064 & 27.294 & 8.124 & 14.693 \\
$\begin{array}{l}\alpha-T C P \\
\text { after sintering }\end{array}$ & 5.621 & 25.617 & 61.858 & 9.042 & 30.494 \\
\hline
\end{tabular}

$4^{\circ} \mathrm{C}$ and all samples were analysed simultaneously with a direct ELISA assay.

ALP activity assay. The bioactivity of synthesised and released rhBMP-2 was determined using an ALP assay. Mouse myoblasts ( $\mathrm{C} 2 \mathrm{C} 12$ cells) were seeded on a 48-well plate and after 24 hours, the media was replaced with $0 \mu \mathrm{g} / \mathrm{ml}$ to $6 \mu \mathrm{g} / \mathrm{ml} \mathrm{BMP-2}$ and the cells were grown for four days. The ALP assay was determined by a standard method. ${ }^{13,14}$ Cell number was identified using the CyQuant assay (Invitrogen, Grand Island, New York). Cells were lysed using lysis buffer $(300 \mu \mathrm{l} /$ well) supplied with the CyQuant kit. DiFMUP (6,9-difluor-4-methylumbelliferylphosphate; Invitrogen) was used as the substrate to determine ALP activity. A total of $50 \mu \mathrm{l}$ of cell lysate from each well were mixed with $50 \mu \mathrm{l}$ DiFMUP solution $(200 \mathrm{mM})$ and then incubated in the dark for 15 mins at $37^{\circ} \mathrm{C}$. Fluorescence was read at $450 \mathrm{~nm}$. The amount of DiFMU (ALP reaction product) was calculated using standard curves for cell number and DiFMU.

Statistical analysis. Statistical significance was determined using Student's $t$-test with Bonferroni's correction, in GraphPad software (GraphPad Inc., La Jolla, California).

\section{RESULTS}

Characterisation of $\alpha$-TCP. XRD showed $>98 \%$ phase purity of $\alpha$-TCP (Fig. 1a). The calculated $\mathrm{Ca} / \mathrm{P}$ molar ratio for $\alpha$-TCP was 1.49, which was comparable to the expected $\mathrm{Ca} / \mathrm{P}$ molar ratio of $1.50 .{ }^{15}$ The sintered $\alpha$-TCP samples were coated with platinum before imaging. SEM images show that each nanoparticle exhibits an elongated morphology measuring approximately $60 \mathrm{~nm}$ in width and $80 \mathrm{~nm}$ in length (Fig. 1b).

TEM revealed the agglomeration of $\alpha$-TCP ceramic nanoparticles. Particle size analysis was performed and Table I shows that sintering increased the agglomeration of nanoparticles.

Characterisation of biodegradable $\alpha$-TCP/PLGA nanocomposite. The $\alpha$-TCP/PLGA nanocomposite produced from the MSE method was hot-pressed into sheets to facilitate the production of discs.

Before hot-pressing, the surface appeared to consist of interconnected pores with a homogeneous distribution of $\alpha$-TCP nanoparticles sized $70 \mathrm{~nm}$ to $80 \mathrm{~nm} \times 100 \mathrm{~nm}$ to $120 \mathrm{~nm}$ (Fig. 2). After hot-pressing, the surface of the 


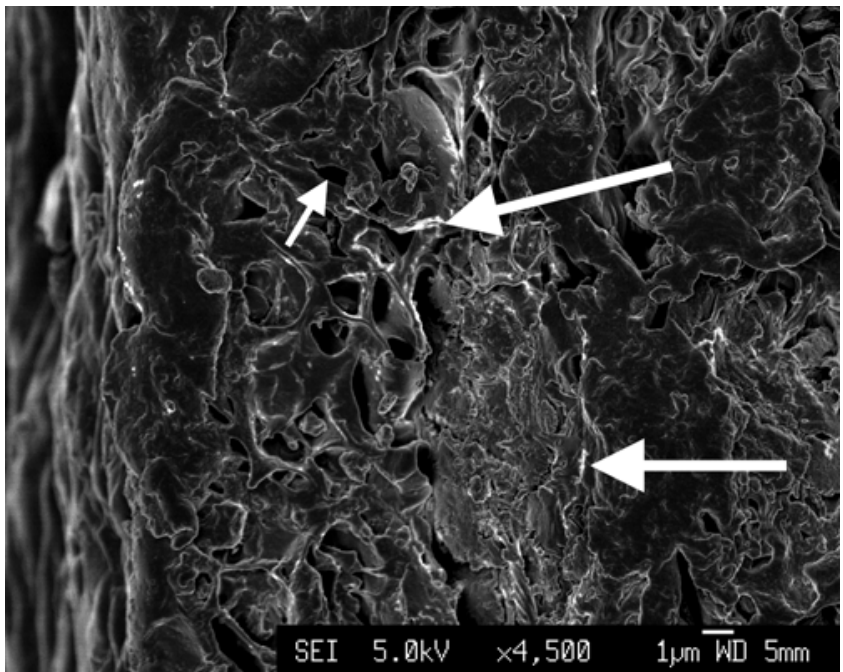

Fig. 2 a

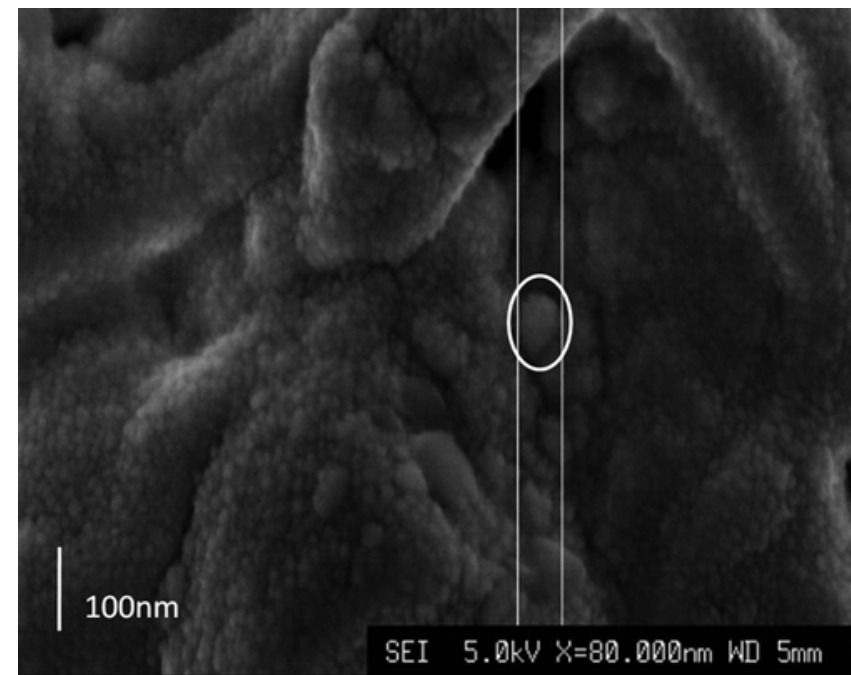

Fig. $2 b$

Scanning electron microscopy images of $\alpha$-tricalcium phosphate/poly(D,L-lactide-co-glycolide) $(\alpha-T C P / P L G A)$ before hot-pressing at a) $\times 4500$ magnification, showing pores (small arrow) and $\alpha$-TCP particles (large arrow), and b) at $\times 80000$ magnification, showing an $\alpha$-TCP particle (circled).

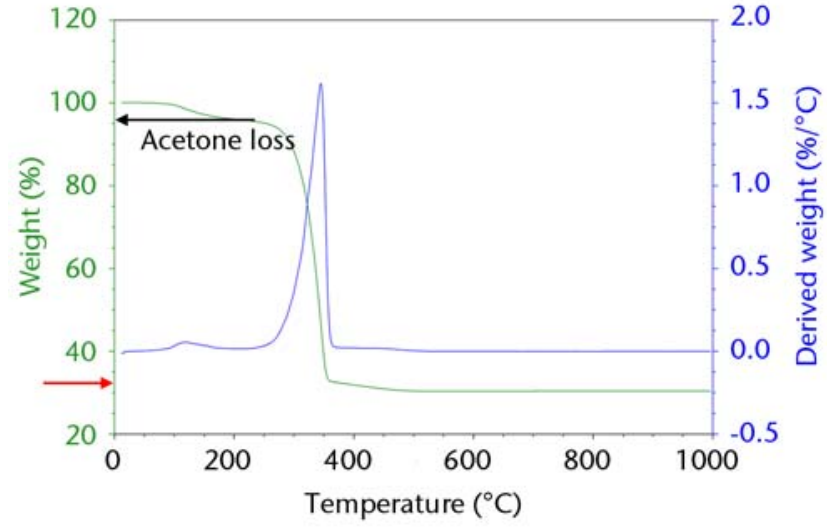

Fig. 3

Plot of thermogravimetric analysis analysis of $\alpha$-tricalcium phosphate, showing actual weight percentage to be $32.03 \%$ (red arrow).

nanocomposite appeared smooth, which results from a high compressive force applied during the fabrication process. The internal surface of the nanocomposite was examined after cutting the composite disc with a sharp blade and SEM examination showed that there was preservation of its inherent porous structure (Fig. 2b), even after the application of high compressive forces and high temperature $\left(150^{\circ} \mathrm{C}\right)$.

To improve the surface properties of the nanocomposite, grinding was performed after hot-pressing, using silicon carbide sandpaper (2400 Grit), which introduced shallow ridges and cavities to aid potential protein adsorption and cell attachment. TGA was performed on the $\alpha$-TCP/PLGA nanocomposite to ascertain the weight percent of ceramic filler. Samples were heated from $37^{\circ} \mathrm{C}$ to $500^{\circ} \mathrm{C}$ at a rate of $10^{\circ} \mathrm{C}$ in a nitrogen atmosphere. The trace observed is shown in Figure 3, from which the actual weight percent of $\alpha$-TCP in the synthesised nanocomposite was calculated to be $32.03 \%$. EDX was used to characterise the homogeneity of the nanocomposite with respect to $\mathrm{Ca}^{2+}, \mathrm{P}^{5+}$, and $\mathrm{O}^{2-}$ ions, and this was found to be homogenous.

Bioactivity of BMP-2. The ALP activity in C2C12 cells was directly proportional to the concentration of BMP-2 up to a concentration of $2 \mu \mathrm{g} / \mathrm{ml}$, at which point further increases in BMP-2 concentration did not increase the ALP activity.

Bioactivity of $30 \% \alpha$-TCP/PLGA/BMP-2 nanocomposite. $5 \times 10^{4}$ C2C12 cells were seeded onto each of the discs of nanocomposite and adsorbed BMP-2 (incubation concentrations of $0,20,40$ and $60 \mu \mathrm{g} / \mathrm{ml}$ ) in $500 \mu$ l of supplemented DMEM. Cells were harvested for an ALP assay (Fig. 4) at four days (using BCA protein assay for protein quantification). ${ }^{16}$

The ALP activity of C2C12 cells was increased by the presence of all BMP-2/nanocomposite discs, compared with the presence of a blank disc ( $p=0.0022$, Student's $t$-test with Bonferroni's correction). Furthermore, the ALP activity increased with increasing incubation concentrations of BMP-2 ( $p=0.0086)$, except for the difference between $20 \mu \mathrm{g} / \mathrm{ml}$ and $40 \mu \mathrm{g} / \mathrm{ml}$ BMP-2 $(p=0.41)$. In vitro release of $\mathrm{BMP}-2$ from nanocomposite. The concentration of BMP-2 adsorbed onto the $\alpha$-TCP/PLGA nanocomposites, as measured by ELISA directly on the discs, correlated well with the incubation concentration of BMP-2, up to an incubation concentration of $25 \mu \mathrm{g} / \mathrm{ml}$ (Fig. 5). Approximately $10 \%$ to $15 \%$ of BMP-2 was adsorbed on to the discs, except at the highest incubation 


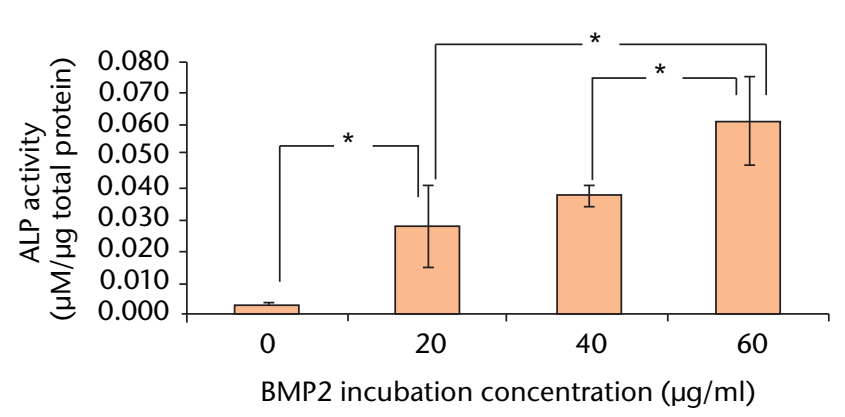

Fig. 4

Bar chart showing the mean alkaline phosphatase (ALP) activity of C2C12 cells (after four days culture on bone morphogenetic protein (BMP)-2/nanocomposite discs) with increasing incubation concentrations of BMP-2 (error bars denote standard deviation) (* $\mathrm{p}<0.0125$, Student's $t$-test with Bonferroni's correction).

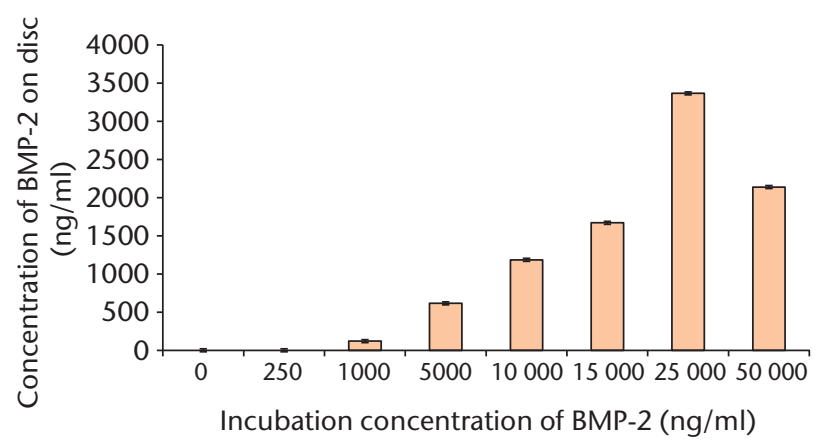

Fig. 5

Bar chart showing the mean concentration of bone morphogenetic protein (BMP)-2 adsorbed onto nanocomposite discs with increasing incubation concentrations of BMP-2 (error bars denote standard deviation).

concentration $(50 \mu \mathrm{g} / \mathrm{ml})$, where only $4 \%$ of the BMP-2 appeared to have been adsorbed. The cumulative release of BMP-2 from 30\% $\alpha$-TCP/PLGA/BMP-2 nanocomposite showed a burst release within the first two hours for all discs and there was minimal release of BMP-2 within the latter time intervals (Fig. 6). In order to determine if there was any remaining adsorbed BMP-2 on the nanocomposite discs, a direct ELISA was performed with the discs from the release study at 72 hours. The remaining BMP-2 on the discs at this time is shown in Figure 7.

\section{Discussion}

The aims of our research were to synthesise and study the release of BMP-2 from a bioresorbable osteoconductive nanocomposite and to assess its suitability for tissue regeneration.

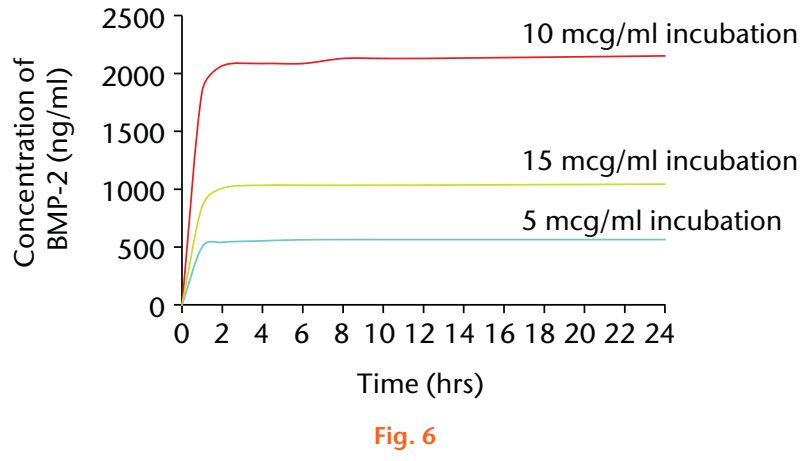

Bar chart showing the cumulative release profile of bone morphogenetic protein (BMP-2) from nanocomposite disc after increasing incubation concentrations of BMP-2, showing an initial burst release.

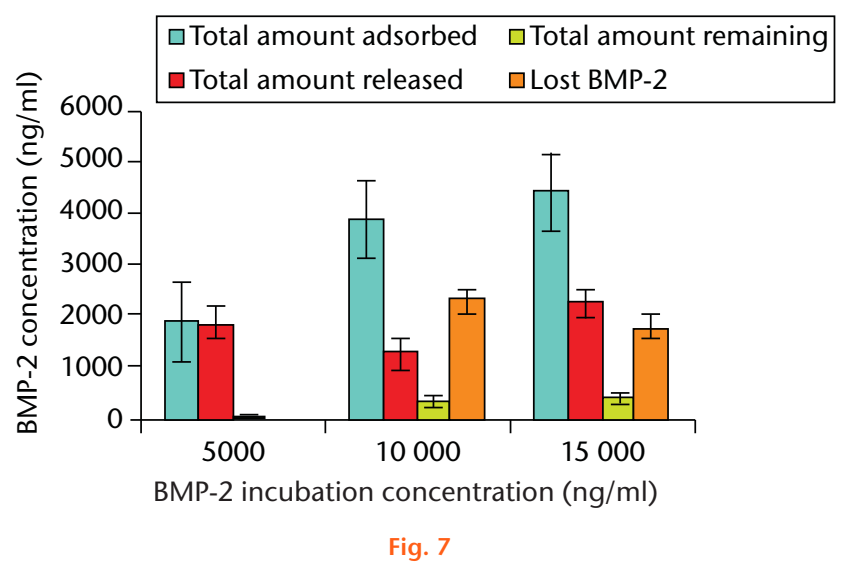

Bar chart showing the mean total amounts of bone morphogenetic protein (BMP)-2 adsorbed onto, released from and subsequently remaining on the nanocomposite discs (error bars denote standard deviation).

Limitations of this study include no comparison of the BMP-2 derived from E. coli expression system with commercially-available BMP-2 from mammalian expression systems. In addition, the nanocomposite was not compared with a similar microcomposite. The ELISA assay used to quantify the BMP-2 is less sensitive than radioactive labelling, although it is less expensive, less timeconsuming and widely used. Finally, there is no data from in vivo studies, which would be required to truly identify the potential of this for clinical application, and such studies are planned.

The commercially-available and FDA-approved BMP products have been produced in mammalian expression systems but, owing to the low yield from such production, are very expensive. As yet, no BMPs produced in E. coli expression systems have received FDA approval for clinical use, although other recombinant proteins from such systems are in regular clinical use (human insulin (Humulin; Eli Lilly, Indianapolis, Indiana); human growth hormone (Nutropin; Genentech, San Francisco, 
California); and human interferon (Bayer, Leverkusen, Germany)). As $E$. coli expression systems result in a very high yield of BMPs, this could lead to a great reduction in the costs of BMPs for clinical use.

The advent of nanotechnology and its use in the production of biomaterials for orthopaedics has led to an increase in interest in its use as a delivery system.

It has been shown that nanoparticles enable greater proliferation of osteoblasts than conventional micro-sized ceramics. ${ }^{17}$ In this study, nanoparticles were produced (Fig. 2). It is known that nanoparticles form agglomerates because of their large surface area and high surface energy. ${ }^{18}$ It has previously been shown that attempts to disperse ceramic nanoparticles result in the heterogeneous distribution of heterogeneous-sized particles. ${ }^{19}$ We achieved homogeneous distribution of nanoparticles throughout the composite, avoiding agglomeration by using the modified solution evaporation (MSE) method. This method combines the external energy of attritor milling and particle-coating using PLGA dissolved in acetone; after the agglomerates of $\alpha$-TCP are broken down into nanoparticles, they will re-agglomerate due to the aforementioned inherent properties of nanoparticles. In order to prevent this, they were immediately coated with the polymer (PLGA) that is dissolved in acetone, and this maintained their nanostructure and homogeneous distribution throughout the nanocomposite.

In addition, this nanocomposite is osteoconductive (supports the ingrowth of capillaries, perivascular tissue and osteoprogenitor cells), as shown by the increased growth of $\mathrm{C} 2 \mathrm{C} 12$ cells on nanocomposite $\alpha$-TCP/PLGA discs when compared with microcomposite $\alpha$-TCP/ PLGA discs. ${ }^{12}$

The formation of tri-calcium phosphate ceramic is dependent on the method of synthesis, the sintering temperature, the amount of impurities present and the heating rate. ${ }^{20,21}$ Both wet precipitation reactions and solid state reactions can be used to synthesise $\alpha$-TCP. The wet precipitation method was used to synthesise $\alpha$-TCP with $>98 \%$ purity (Fig. 1a) by using a high-grade calcium hydroxide, a sintering temperature of $1400^{\circ} \mathrm{C}$ and rapid quenching to room temperature.

Although the surface of this nanocomposite is smooth, it was also shown that grinding resulted in roughness of the surface, which could potentially improve cell attachment and drug/protein adsorption. This suggests that it might have a practical use as bone void filler or a drug-delivery system. In addition, as the nanocomposite degrades, the porous core will be exposed. This interconnected porous structure may help cells proliferate by providing anchoring sites and channels for the delivery of nutrients, whilst facilitating angiogenesis. In addition, this porous structure is likely to have an effect on degradation.

BMP-2 was successfully adsorbed onto the surface of $\alpha$ TCP/PLGA nanocomposite, as shown by the ELISA assay (Fig. 5). Increasing incubation concentrations of BMP-2 resulted in an increase of detected adsorbed BMP-2 on the discs (Fig. 5), however this was not observed at the highest incubation concentration $(50 \mu \mathrm{g} / \mathrm{ml})$. As adsorption of BMP-2 onto the ground surface of the $\alpha$-TCP/PLGA nanocomposite occurs primarily through electrostatic interactions between cationic BMP-2 and anionic $\alpha$ $\mathrm{TCP},{ }^{22-24}$ this might reflect saturation in adsorption secondary to saturation of surface anionic $\alpha$-TCP by BMP-2. It might also reflect heterogeneity of the discs' content and surface area, or a combination of both these factors. In addition, the majority, but not all, of the BMP-2 adsorbed was either released or remained on the surface of the disc and was detectable by ELISA (Fig. 7). This means that a small proportion of BMP-2 was neither released nor detectable on the surface of the discs, suggesting that it was either 'lost' (adsorbed onto the surface of the plate during the ELISA assay) or absorbed by the nanocomposite discs during the 72-hour release study.

Adsorbed BMP-2 was shown to have bioactivity that increased with increasing incubation concentrations of BMP-2 (Fig. 4). This was shown to be statistically significant and suggests this nanocomposite could have osteoinductive potential in vivo, with BMP-2 adsorbed at the surface at the material being sufficient to promote rapid bone healing. Future work will include in vivo studies in order to determine if this is the case.

The release study shows that the majority of adsorbed BMP-2 was released from the nanocomposite within two hours. This burst pattern of BMP-2 release has been shown previously from BMP adsorbed onto $\mathrm{mPCL} /$ collagen/HA composite (as for many other composites) and this significantly increased the bone formation of critical-sized defects. $^{25}$ The release of a growth factor can be either diffusion-controlled, chemical reaction-controlled, solventcontrolled, or a combination of these mechanisms. ${ }^{26}$ BMP release from within the pores of porous scaffolds is diffusion-controlled, whereas BMP that is physically immobilised in a carrier matrix and released by its degradation is a chemical reaction-controlled system. The rate of release also depends on the molecular weight of the BMP, its conformation and its solubility. ${ }^{27}$ Although the optimal release pattern will be specific both to the material and BMP used, and the nature and size of the defect, the ideal delivery system would provide release for a period of time sufficient for bone growth. While a more sustained release profile of BMP-2 is generally considered desirable, this might be of more relevance to delivery systems that do not possess any inherent biological activity. The early burst release of BMP2 , which has been shown for this nanocomposite of $\alpha-T C P /$ PLGA/BMP-2, could promote the differentiation of mesenchymal cells into osteoblasts. The proliferation of these might then be sustained by the nanocomposite itself, without the need for the sustained delivery of BMP-2.

We have successfully produced a nanocomposite using the MSE method that combines the osteoconductivity properties of ceramics and bioresorbability of polymer 
producing a three-dimensional scaffold for bone regeneration. Bioactive BMP-2 produced in $E$. coli and refolded to an active form has been adsorbed onto and subsequently released from this nanocomposite. This material therefore has potential application as an osteoinductive agent in regenerative medicine.

\section{References}

1. Urist MR. Bone: formation by autoinduction. Science 1965;150:893-899.

2. No authors listed. Musculoskeletal injuries report: incidence, risk factors and prevention. Rosemont: American Academy of Orthopaedic Surgeons, 2000.

3. Dimitriou R, Mataliotakis GI, Angoules AG, Kanakaris NK, Giannoudis PV. Complications following autologous bone graft harvesting from the iliac crest and using the RIA: a systematic review. Injury 2011;42(Suppl 2):S3-S15.

4. Prokuski LJ, Marsh JL. Segmental bone deficiency after acute trauma: the role of bone transport. 0 rthop Clin North Am 1994;25:753-763.

5. Dimitriou R, Jones E, McGonagle D, Giannoudis PV. Bone regeneration: current concepts and future directions. BMC Med 2011;9:66.

6. Poynton AR, Lane JM. Safety profile for the clinical use of bone morphogenetic proteins in the spine. Spine (Phila Pa 1976) 2002;27(Suppl 1):S40-S48.

7. Mont MA, Ragland PS, Biggins B, et al. Use of bone morphogenetic proteins for musculoskeletal applications: an overview. J Bone Joint Surg [Am] 2004;86-A(Suppl 2): $41-55$.

8. Geiger M, Li RH, Friess W. Collagen sponges for bone regeneration with rhBMP-2. Adv Drug Deliv Rev 2003;55:1613-1629.

9. Haidar ZS, Hamdy RC, Tabrizian M. Delivery of recombinant bone morphogenetic proteins for bone regeneration and repair. Part A: Current challenges in BMP delivery. Biotechnol Lett 2009;31:1817-1824.

10. Haidar ZS, Hamdy RC, Tabrizian M. Delivery of recombinant bone morphogenetic proteins for bone regeneration and repair. Part B: Delivery systems for BMPs in orthopaedic and craniofacial tissue engineering. Biotechnol Lett 2009;31:1825-1835.

11. Okubo Y, Bessho K, Fujimura K, et al. Osteoinduction by recombinant human bone morphogenetic protein-2 at intramuscular, intermuscular, subcutaneous and intrafatty sites. Int J Oral Maxillofac Surg 2000;29:62-66

12. Yang Z, Best $S$, Cameron R. The influence of $\alpha$-tricalcium phosphate nanoparticles and microparticles on the degradation of poly(D,L-lactide-co-glycolide). Advanced Materials 2009;21:3900-3904.

13. Bessey $\mathbf{0 A}$, Lowry $\mathbf{0 H}$, Brock MJ. A method for the rapid determination of alkaline phosphates with five cubic millimeters of serum. J Biol Chem 1946;164:321-329.

14. Kirsch T, Nickel J, Sebald W. BMP-2 antagonists emerge from alterations in the low-affinity binding epitope for receptor BMPR-II. EMBO J 2000;19:3314-3324.

15. Ratner BD, Hoffman AS, Schoen FJ, Lemons JE. Biomaterials science: an introduction to materials in medicine. San Diego: Elsevier, 2004.
16. Smith PK, Krohn RI, Hermanson GT, et al. Measurement of protein using bicinchoninic acid. Anal Biochem 1985;150:76-85.

17. Webster TJ, Ergun C, Doremus RH, Siegel RW, Bizios R. Enhanced functions of osteoblasts on nanophase ceramics. Biomaterials 2000;21:1803-1810.

18. Siegel RW. Nanophase materials: synthesis, structure and properties. In: Fujita FE, ed. Physics of new materials. Berlin: Springer-Verlag, 1994.

19. Tampieri A, Celotti G, Landi E, et al. Biologically inspired synthesis of bone-like composite: self-assembled collagen fibers/hydroxyapatite nanocrystals. J Biomed Mater Res A 2003;67:618-625.

20. Ando J. Tricalcium phosphate and its variation. Bull Chem Soc 1958;31:196-201.

21. LeGeros RZ, Kijkowska R, Bautista C, LeGeros JP. Synergistic effects of magnesium and carbonate on properties of biological and synthetic apatites. Connect Tissue Res 1995;33:203-209.

22. Koenig BB, Cook JS, Wolsing DH, et al. Characterization and cloning of a receptor for BMP-2 and BMP-4 from NIH 3T3 cells. Mol Cell Biol 1994;14:5961-5974.

23. Smeets R, Kolk A, Gerressen M, et al. A new biphasic osteoinductive calcium composite material with a negative Zeta potential for bone augmentation. Head Face Med 2009;5:13

24. Smith I0, Baumann MJ, McCabe LR. Electrostatic interactions as a predictor for osteoblast attachment to biomaterials. J Biomed Mater Res A 2004;70:436-441.

25. Sawyer AA, Song SJ, Susanto E, et al. The stimulation of healing within a rat calvarial defect by $\mathrm{mPCL}-\mathrm{TCP} / \mathrm{colllagen}$ scaffolds loaded with rhBMP-2. Biomaterials 2009:30:2479-2488

26. LuginbuehI V, Meinel L, Merkle HP, Gander B. Localized delivery of growth factors for bone repair. Eur J Pharm Biopharm 2004;58:197-208.

27. Kirker-Head CA. Potential applications and delivery strategies for bone morphogenetic proteins. Adv Drug Deliv Rev 2000;43:65-92.

Funding statement:

- Grants were received from the Engineering and Physical Sciences Research Council (EPSRC) and the National Institute for Health Research (NIHR).

Author contributions:

- A. Sharma: Study design, Data collection, Data analysis, Statistical analysis, Writing the paper

- F. Meyer: Data collection, Writing the paper

- M. Hyvonen: Study design, Data collection, Data analysis

- S. M. Best: Study design

- R. E. Cameron: Study design

N. Rushton: Study design

ICMJE Conflict of Interest:

- None declared

(C)2012 British Editorial Society of Bone and Joint Surgery. This is an open-access article distributed under the terms of the Creative Commons Attributions licence, which permits unrestricted use, distribution, and reproduction in any medium, but not for commercial gain, provided the original author and source are credited. 